\title{
REVISED A Key Role for the Genetic Counsellor in the Genomics
}

\section{Era [version 2; peer review: 2 approved, 1 approved with}

\section{reservations]}

Previously titled: The possible implications of advances in genetic testing technologies for Genetic Counsellors working with families of children with developmental disorders

Flora M. Joseph

All Wales Medical Genetics Service, Cardiff, UK

V2 First published: 03 Apr 2018, 7:420

https://doi.org/10.12688/f1000research.14222.1

Latest published: $17 \mathrm{Dec}$ 2018, 7:420

https://doi.org/10.12688/f1000research.14222.2

\section{Abstract}

New genetic testing technologies such as microarrays and whole exome sequencing mean the diagnostic potential for a child with a development disorder is greatly increased over traditional testing techniques. With this increased potential comes increased expectations from families and professionals about the answers a diagnosis will provide. However, limitations remain and a proportion of individuals will continue to remain undiagnosed. In addition, some individuals will receive novel or very rare diagnoses about which very little is known in terms of prognosis and effective treatments. In this paper, I present an argument for why these families would benefit from additional Genetic Counsellor support and how Clinical Genetics services in the UK could provide this support. I acknowledge that resources are limited, but as demands on services increase and interactions with families become shorter, I argue that this kind of service should be prioritised, for the benefit of these families.

\section{Keywords}

genetic counseling, genetic services, genetic testing, intellectual disability, developmental disabilities, psychosocial support systems, uncertainty, psychological adaptation

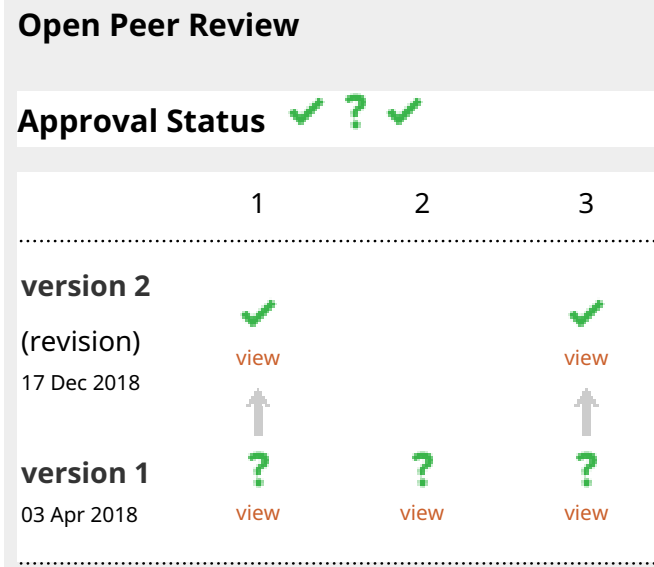

1. Maria Soller, Karolinska University Hospital, Stockholm, Sweden

Charlotta Ingvoldstad Malmgren, Uppsala University, Uppsala, Sweden

Karolinska University Hospital, Stockholm, Sweden

2. Vicki Wiles, Addenbrookes Hospital,

Cambridge, UK

Sue Kenwrick, Addenbrookes Hospital, Cambridge, UK

3. Andrew Cuthbert ID, Cardiff University, Cardiff, UK

Any reports and responses or comments on the article can be found at the end of the article. 
Corresponding author: Flora M. Joseph (flora.joseph@wales.nhs.uk)

Author roles: Joseph FM: Conceptualization, Visualization, Writing - Original Draft Preparation, Writing - Review \& Editing Competing interests: No competing interests were disclosed.

Grant information: The author(s) declared that no grants were involved in supporting this work.

Copyright: $\odot 2018$ Joseph FM. This is an open access article distributed under the terms of the Creative Commons Attribution License, which permits unrestricted use, distribution, and reproduction in any medium, provided the original work is properly cited.

How to cite this article: Joseph FM. A Key Role for the Genetic Counsellor in the Genomics Era [version 2; peer review: 2 approved, 1 approved with reservations] F1000Research 2018, 7:420 https://doi.org/10.12688/f1000research.14222.2

First published: 03 Apr 2018, 7:420 https://doi.org/10.12688/f1000research.14222.1 


\section{REVISED Amendments from Version 1}

I have amended the title to make it more concise.

I have taken on board the comments about the reduction in pre-clinic work ups by Genetic Counsellors and changed my suggestions to focus more on post-clinic/post-test follow up instead.

I have restructured the article to make it more reader-friendly I have included more detail about the training of Genetic Counsellors in the UK

See referee reports

\section{Introduction}

Projects such as the Deciphering Developmental Disorders (DDD) study, and the 100,000 Genomes project, have used whole exome or genome sequencing to pinpoint disease causing mutations (Firth \& Wright, 2011; Genomics England, 2018), increasing the chance of making a diagnosis in individuals with developmental disorders. This type of technology is a realistic possibility for clinical NHS care in the UK within the not-too-distant future (Hazelton \& Petchey, 2015). In this paper, I explore the implications this could have for the support needs of families of children with developmental disorders as they go through the diagnostic journey. I discuss the role that Genetic Counsellors can play in meeting these support needs and argue that extending the role in the post-testing stage would benefit these families.

Developmental disorders may manifest in any area of development (e.g. growth, congenital malformations, seizures) but the most common phenotype is developmental delay (DD) or intellectual disability (ID) (Deciphering Developmental Disorders Study, 2015) which are common referral indicators to Clinical Genetic Services. DD may present itself in any of the following areas: gross/fine motor skills, speech/language, cognition, social/ personal, and activities of daily living (Shavell et al., 2003). If a child has delay in two or more of these areas they are said to have Global Developmental Delay (GDD). The estimated prevalence of GDD is about the same as ID at approximately $1-3 \%$. It is estimated that $5-10 \%$ of all children have some sort of DD, therefore DD or even GDD may not necessarily lead to ID, but children with ID often had DD in their early years (Shavell et al., 2003).

\section{Diagnostic tools employed for individuals with developmental disorders}

Traditionally, those fulfilling the clinical features of a recognised syndrome may be diagnosed on clinical examination alone. As technology has advanced, other diagnostic tools have become available, such as metabolic studies, EEG, CT/MRI imaging, cytogenetic studies (e.g. karyotype, FISH studies, subtelomeric studies, etc), and single-gene targeted testing (Rauch et al., 2006; Shavell et al., 2003). Until the advent of more recent technologies (array $\mathrm{CGH}$ and next generation sequencing), these tools gave a diagnostic yield for children with GDD/ID in the region of 50-70\% (Daily et al., 2000; Rauch et al., 2006). Therefore, up to half of children with GDD/ID remained undiagnosed.
'Molecular karyotyping' or 'array Comparative Genomic Hybridisation' (array CGH) is a technique that came into clinical practice across the UK during the first decade of the 21st century (Rauch et al., 2006). Array CGH identifies sub-microscopic genetic imbalances across the genome. It can identify copy number variants (changes in the number of copies) of genes which may affect health or development. It allows much more detailed cytogenetic analysis and in most parts of the UK has become a first-line test, superseding traditional cytogenetic studies. Array CGH gives an average diagnostic yield of 15-20\% (Miller et al., 2010) for individuals who have not received a diagnosis using other methods. As our knowledge advances, it is hoped the classification of variants of uncertain significance will improve, which could increase this diagnostic yield.

The Deciphering Developmental Disorders (DDD) study was a UK-based study sequencing the exomes of children with undiagnosed developmental disorders (Firth \& Wright, 2011). Exomes are the coding regions of our genes, and account for about $1 \%$ of all our genetic material (Wang et al., 2013). The DDD study hoped that a molecular diagnosis could be found by comparison of a child's exome with their parents' (Firth \& Wright, 2011). A diagnostic yield of 31\% was reported from the first 1133 trios (children and both parents) recruited to the study, and 12 new developmental genes were discovered (Deciphering Developmental Disorders Study, 2015). An American-based study sequencing clinical exomes also found a diagnostic yield of $31 \%$ for trios, and $22 \%$ for proband-only cases (Lee et al., 2014). The diagnostic yield is expected to increase as new genes are described and further analysis takes place.

\section{Responses and support needs of parents adapting to} having a child with a developmental disorder

It is natural for parents to hope for a healthy child. The point when a developmental disorder may become apparent can range from a prenatal scan, to birth, to later on as the child grows. This can be a sudden or a gradual realisation (Heiman, 2002; Lewis et al., 2010). Initial reactions to this realisation are likely to be negative such as disbelief, anger, denial, and grief (Graungaard \& Skov, 2007; Heiman, 2002; Kearney \& Griffin, 2001; Lewis et al., 2010). From this initial reaction, parents must go through a process of adaptation of "replacing the hopes and expectations...with the realities of their child's actual prognosis" (pg 186, Barnett et al., 2003). This process has been likened to that of a 'journey' that at times is like a 'rollercoaster' full of highs and lows (Lewis et al., 2010).

For parents to adjust appropriately to the reality of having a disabled child, they must adopt a number of coping strategies. These may be practically or emotionally-directed (Graungaard \& Skov, 2007; Lewis et al., 2010; Rosenthal et al., 2001). Practical coping strategies may be information gathering e.g. about disease prognosis, treatments or research opportunities. Emotional coping strategies may be talking with friends and family or accessing support services. Some of the studies cited earlier went on to explore parental feelings after they have gone through this period of adaptation. They found that many parents have positive and optimistic feelings about their child's future (Heiman, 2002; Kearney \& Griffin, 2001; Lewis et al., 2010). 
Although the majority of parents appear to adapt well to their new reality, some parents and families are less successful. Traits of less successful adaptation may be: unrealistic appreciation of their child's weaknesses and limitations; continued feelings of self-pity and guilt; searching for a 'magical solution'; and feelings of rejection or over-protection of their child, sometimes at the expense of other family members (Kandel \& Merrick, 2007). This inability to cope and adapt can have a negative effect on mental health (e.g. stress, depression), relationships and functioning (Barnett et al., 2003).

A developmental disorder can leave families with many questions, some of which can only be answered by obtaining an accurate diagnosis. In this way, searching for a diagnosis can form part of the process of coping and adaptation. Below is a list of reasons given for seeking a diagnosis that has been amalgamated from a range of studies. Most of these studies are of parents of children with developmental disorders, but one includes responses from adults with genetic disorders (Hazelton \& Petchey, 2015). A range of methods were used including semi-structured interviews (Lewis et al., 2010; Makela et al., 2009; Rosenthal et al., 2001) and surveys (Hazelton \& Petchey, 2015; Limb et al., 2010; Madeo et al., 2012).

- To provide information about progression and prognosis for their child to make life plans and help form realistic expectations for the future

- To be aware of recurrence risk for future pregnancies and whether pre-natal testing or carrier testing is available for relatives

- To guide clinical management e.g. whether any additional clinical surveillance is recommended or whether any treatments, therapies or diets are known to be ineffective/ harmful for that condition

- To have 'a label'. Both positive and negative associations were attributed to this. For example, a benefit is having a term to explain why their child is different from other children. However, a concern is that it may cause their child to be stereotyped and people, such as teachers, to have reduced expectations of their abilities

- To improve access to support services (e.g. education, health or social services). Although this should be based on need regardless of diagnosis, this has been reported to be easier when a diagnosis is known (Rosenthal et al., 2001)

- To improve access to peer support of families in a similar situation as themselves. Without a diagnosis, there can be increased feelings of isolation

- To have 'an answer'. This can provide psychological relief to keep from wondering why this has happened and increase perceived feelings of control

Rosenthal et al. (2001) and Lewis et al. (2010) each conducted semi-structured interviews with parents of children with developmental disorders either in the USA (Rosenthal group) or the
UK (Lewis group). The purpose of these studies was to find out what impact a lack of diagnosis had on parental adjustment and coping. There was a wide range in the length of time that parents had been aware of their child's difficulties in both studies, which provides useful information about how coping and adaptation may change over time. Similar reactions to the initial recognition of a problem were reported by parents whether a child had a known diagnosis or not (Lewis et al., 2010). However, in the absence of a diagnosis, additional challenges were noted which could result in a longer period of adjustment and adaptation (Barnett et al., 2003; Heiman, 2002; Lewis et al., 2010; Rosenthal et al., 2001).

A lack of diagnosis means there is greater uncertainty. Madeo et al. (2012) looked at the effect of uncertainty on parental coping and adaptation to raising a child with a developmental disorder. Lipinski et al. (2006) also looked at factors associated with parental uncertainty and perceived control, and the role they played in coping and adaptation for parents of children with a rare chromosome disorder (prevalence of $1 / 120,000$ or lower), which provides useful information about families with novel or very rare conditions. Both studies used a mixed-methods survey (either paper or computer-based) and had relatively large sample sizes (266 and 363 respectively). Madeo et al. (2012) discussed that uncertainty can sometimes aid coping, as it leaves room for optimism of a positive outcome. However, in the majority of cases, both studies found that uncertainty perpetuated a feeling of lacking control over their child's condition, which was linked to poorer coping and a longer process of adaptation, as reported by Rosenthal et al. (2001) and Lewis et al. (2010). Both Lipinski et al. (2006) and Madeo et al. (2012) found factors that were associated with lower perceived control were being less optimistic about the future and perceiving their child's condition as more severe. Lipinski et al. (2006) found younger parents felt greater uncertainty but this was not replicated by Madeo et al. (2012), although the latter study population did not have a very wide age range. These studies help to explain why a lack of diagnosis, or the diagnosis of a very rare or novel condition, often results in an extended period of coping and adaptation and therefore why additional support may be appropriate.

As one parent from the Genetic Alliance UK patient charter commented "We always imagined that getting a diagnosis would be the final piece of the puzzle and the end of the journey, but it now feels as if we are at the very beginning of a new journey" (pg 9, Hazelton \& Petchey, 2015). Another parent, whose child was found to have a unique unbalanced translocation, used the term 'non-diagnosis' as there was no prognostic information available and commented "It's like being told something in a foreign language. It wasn't a relief because I didn't understand it" (pg 810, Lewis et al., 2010). For these parents the diagnosis had not brought all the answers they had hoped for.

Parents described how the desire for a diagnosis diminished over time, as the child grew older, however often it never completely went away (Lewis et al., 2010; Rosenthal et al., 2001). In part, this may be due to becoming more familiar with their child's condition as they grow, and forming a clearer idea of what 
the future may be like. It addition, this may be due to the realisation that a diagnosis will not change who their child is. However, there are times that re-kindle the desire for a diagnosis e.g. when the child is approaching adulthood and applying for additional support (e.g. supported housing), or when siblings are reaching reproductive age, and additional support could also be appropriate at these times.

As genetic testing becomes more accessible and diagnostic rates increase, I wonder how this will affect the support needs of families. Even though diagnostic rates will improve, there will undoubtedly be individuals who remain undiagnosed. In addition, there will be a growing number of individuals who are given a novel molecular diagnosis, about which very little may be known. While these families may receive answers to some of their questions, others will remain unanswered. I wonder whether the current role of the Genetic Counsellor is sufficient to meet the needs of these families, or whether adaptations to the role could meet the need better.

\section{The role of the Genetic Counsellor}

Biesecker (pg 327, 2001) discussed the goals of genetic counselling and stated that "contemporary genetic counselling should strive to... facilitate clients' ability to use genetic information in a personally meaningful way that minimises psychological distress and increases personal control". Genetic Counselling can be provided by clinicians with specialist training in genetics. Traditionally this has predominantly been Clinical Geneticists and Genetic Counsellors/Genetic Nurse Specialists. As genetic testing becomes more mainstreamed this has broadening to include a wider range of clinicians such as Paediatricians, Oncologists, Cardiologists, Obstetricians and Specialist Nurses working in these areas (Middleton et al., 2015; Welsh Government, 2017). In the UK, Genetic Counsellors work alongside Clinical Geneticists and Clinical Scientists. Whereas other specialities may have detailed discussions about a test result, and be empathetic with a patient, they are unlikely to discuss familial implications and have capacity to have lengthy discussions about emotional impact and processing, so Genetic Counsellors have the capacity for more detailed discussion and exploration of these implications (Middleton et al., 2015).

Current training programmes in the UK are through a Masters programme, 2 or 3 years in length, which includes training in the science of genomics, counselling theory and practical experience in Regional Genetics centres (AGNC, 2018). The current training programmes started in 2017 in response to the move towards more genomic testing and include a larger focus on interpretation of genomic results. Therefore, Genetic Counsellors trained prior to this may feel the need for further training in genomic testing, result interpretation and the limitations of advanced genetic testing technologies in order to appropriately counsel families.

Families are for the most part resilient, but the process of coping and adaptation still benefits from psychological support, regardless of whether a child receives a diagnosis or not (Barnett et al., 2003; Lewis et al., 2010). Seymour Kessler described two models of practice for Genetic Counsellors, a 'teaching model' and a 'counselling model' (Kessler, 1997). Kessler suggests that a hybrid approach is adopted incorporating elements of both so that the counselee has received the appropriate information but has also had time and space for discussion of the consequences and personal reflection. However, a number of studies have examined modern practice and found that the 'teaching model' is more often adopted, with the main purpose of information provision (Lerner et al., 2014; Meiser et al., 2008; Roter et al., 2006; Walser et al., 2017). Austin et al. (2014) reviewed the available literature and found that a 'counselling model' with the aim of addressing the psychosocial concerns, is reported to be associated with increased knowledge retention, reduced anxiety and higher satisfaction with decision-related outcomes. The authors go on to suggest that Genetic Counsellors focus more on this style in their practice. This is supported by Lipinski et al. (2006) who looked at the perceived helpfulness of genetic counselling, for parents of children with developmental disorders. The authors found that it was perceived as more helpful when parents were helped to increase a sense of perceived control over their child's condition (Lipinski et al., 2006) which fits more with a 'counselling model' of practice. A study from the USA looking at the result-giving appointment of exome sequencing highlighted that these appointments were informationheavy and often missed opportunities to build relationships with patients (Walser et al., 2017). The counselling element tended to be neglected due to time restraints and so an on-going relationship with these families would be particular important, to improve understanding, reduce misconceptions, address frustration and disappointment, and improve satisfaction.

Genetic Counsellors have historically had the resources to offer long-term support to families in the UK. Co-counselling with Clinical Geneticists, where they would see patients together, also use to be more common. However, as demands on Genetic Services have increased, time restraints have limited the amount of contact Genetic Counsellors are able to offer families, and relationships have become shorter-term and co-counselling has reduced. Therefore, even though the need for support still exists, families may not request it as they may not recognise where this form of support is best sought (Lipinski et al., 2006). Genetic testing and genetic understanding is infiltrating many areas of healthcare, and the role of Genetic Counsellors as 'information providers' is becoming less specialised (Austin et al., 2014) however Genetic Counsellors have a unique set of skills and can play an important role in providing psychological support for families (Lipinski et al., 2006; Middleton et al., 2017). Austin et al. (2014) propose genetic counselling is remodelled "as a time-limited, highly circumscribed psychotherapeutic encounter". Whereas there is some support for this (Wynn, 2016), from my own experience I feel there is doubt about whether this sort of service is viable in the UK at the moment, due to increased demands and limited resources. I would like to see the profession working towards this sort of model for families of 
children with developmental disorders and I describe below how this could look in practice.

\section{Implications for Genetic Counselling practice}

Genetic testing is becoming more mainstreamed, in some cases without Clinical Genetics involvement. In addition, due to increases in referrals to Clinical Genetics, initial information gathering from families (which has historically been the role of the Genetic Counsellor and an opportunity to assess how families are coping) varies between regional Genetics Services in the UK and is sometimes being carried out by family history coordinators or by postal questionnaires. Therefore the opportunity for pretest counselling by a specialist in Genetics is reducing. With the vast amount of information that can be generated from genomic testing, I see the real value of the Genetic Counsellor's role being in the post-testing period, where the emotional and familial context can be explored (Middleton et al., 2015). Whereas there is already often an open-door policy for families to have followup appointments in many genetics services, families may not recognise where this support is best sought, as mentioned above (Lipinski et al., 2006). I propose that for some families, it may be beneficial to build in routine post-test follow up to the patient pathway. As many Genetic Services are already under great pressure with current demands, adding this additional service may not currently be viable. However, the need for extra funding into genomics in healthcare is being recognised as demonstrated in the Welsh Government's 'Genomics for Precision Medicine Strategy' (2017). This describes the anticipated increase in genomic testing and the increased demand this will put on clinical genetics services. It states that funding will be needed to increase the clinical genetics workforce and for the increased training needs of genetic and non-genetic staff. In addition, it describes how patient experiences will drive service improvements and recognises that Clinical Geneticists and Genetic Counsellors are key elements in providing a good patient experience. Therefore I would hope that the kind of service I describe could be included in future planning.

\section{Proposed aims for a post-test Genetic Counsellor clinic}

For families identified as needing additional support, a timelimited intervention (e.g. 1-3 Genetic Counsellor consultations) could be offered. The aims would be to minimise psychological distress, increase personal control and either i) help them cope with an uncertain future in the absence of a diagnosis, or ii) readjust to having a diagnosis for their child, including coping with the uncertainties this brings if this is for a very rare or novel condition.

Whereas all families may benefit from extra support, I feel some families would benefit in particular, as I describe below.

\section{Identifying families in need}

Once all available investigations have been exhausted, or if results are not expected for a very long time (e.g. via a research study), patients could be considered for the post-test Genetic Counsellor clinic. Indicators for additional support may be:

- The family have lower levels of perceived control/increased levels of uncertainty
- The family have a lack of social support

- The affected person has a novel or very rare diagnosis about which little information is known

- The affected person remains undiagnosed

Assessing perceived control. Increasing personal control over the situation aids coping and adaption (Biesecker, 2001; Lipinski et al., 2006; Madeo et al., 2012). As Lipinski et al. (2006) and Madeo et al. (2012) found, lower perceived control is associated with being less optimistic about the future and perceiving their child's condition as more severe. Therefore, families with these indications may benefit from additional support. One suggestion is to use the Revised Life Orientation Test (LOT-R) which rates 10 statements to assess optimism (Madeo et al., 2012).

When there are high levels of uncertainty, emotional-focused coping strategies are often required to increase perceived control over the situation (Lipinski et al., 2006). The Negative Mood Regulation (NMR) scale is a 30 point scale that measures a person's belief in their own emotion-focused coping resources and may be a helpful way of identifying families in need (Catanzaro \& Mearns, 1990). Asking families about their child's abilities compared to healthy children of the same age might give an indication of their perceptions of the severity of the child's condition and if there is a great difference between the parents' and the clinician's perceptions, further clarification may reduce perceived uncertainty (Madeo et al., 2012).

Another indicator may be the time elapsed since recognition that their child has a developmental disorder. Rosenthal et al. (2001) and Lewis et al. (2010) found the desire for finding a diagnosis decreased with time. Therefore, families nearer the beginning of their journey may benefit more from additional Genetic Counsellor support (Lipinski et al., 2006).

Assessing sources of social support. By asking what sources of support the family have around them, or who they talk to about their child, families may be identified that are experiencing isolation and are in greater need of additional intervention. To effectively highlight families in need, a proforma could be designed that asks for the indicators specified that could be completed by the relevant Clinician (Clinical Geneticist or Genetic Counsellor) to refer the family for the post-test Genetic Counsellor clinic. Alternatively a questionnaire could be included with a post-clinic letter, asking questions around perceived control, optimism and support, to be returned should the family wish to engage with further support.

Proposed model for a post-test Genetic Counsellor clinic The objectives of the session could be:

- Elicit and address concerns

- Discuss strategies for increasing perceived control

- Signpost to other sources of support 
Eliciting and Addressing concerns. For families of children with a developmental disorder, it may be that some of their concerns are hindering their ability to adapt to their child's condition (Graungaard \& Skov, 2006; Rosenthal et al., 2001). Families who place a greater significance on finding a diagnosis may struggle more if one is not made. However, by exploring their reasons for seeking a diagnosis, the Genetic Counsellor may be able to help them find resolution to their concerns, even in the absence of a diagnosis, for example, by accessing peer-support.

Another concern that could be discussed in the absence of a diagnosis, is having a term or label for their child to use with other professionals, or with friends and family e.g. 'developmental delay', 'a SWAN child' (after the support group Syndromes Without A Name) (Lewis et al., 2010). The Genetic Counsellor, in partnership with the Clinical Geneticist, could help families to come up with terminology they can use.

Discussing strategies for increasing perceived control. For the questions that cannot be answered (e.g. prognosis or recurrence risk) families will continue to have a degree of uncertainty, which may perpetuate a feeling of lacking control. As Lipinski et al. (2006) found, genetic counselling was perceived as more helpful when parents are helped to increase a sense of perceived control over their child's condition. Madeo et al. (2012) suggests Genetic Counsellors may help families by identifying areas where they do have some control. The authors suggest training in interventions, such as Coping Effectiveness Training "in which individuals identify the controllable and uncontrollable aspects of their situation and are assisted in identifying coping strategies that are predicted to best match the controllability of the stressor" (Madeo et al., 2012).

Practical-focussed strategies, such as information gathering, may give an increased perception of control (Madeo et al., 2012). Lewis et al. (2010) provides some other suggestions given during interviews with parents. Examples of these are (Lewis et al., 2010; Madeo et al., 2012):

- Keeping a diary to monitor their child's condition and progress. This will not only serve as a useful tool when talking to health care providers, but can also act as a reminder of the progress their child has made

- Developing 'a passport' of their child's likes/dislikes, what they can/can't do, and their medical problems can aid communication with professionals

- Learning about medicine and treatments that are being offered for their child. In this way parents can feel they are making more informed decisions about management

- Becoming experts and advocates for their child's condition. Rosenthal et al. (2001) found that parents who felt informed about their child's problems felt empowered to act as advocates for them in obtaining support services (e.g. educational).

- Contributing to fundraising or research for their child's condition or for rare diseases in general. Rosenthal et al. (2001) found a keenness from parents to engage in activities such as these, so that their child's disability may benefit others

- Setting up a blog or website about their child. This can be both therapeutic and create opportunities for networking and advocacy

However, when there is a high level of uncertainty, practical coping strategies may not be successful and may reduce perceived control due to a lack of available information. In these instances, emotion-focussed strategies may increase perceived feelings of control as "one's internal state may be more amenable to change than the situation itself" (pg 239, Lipinski et al., 2006). These coping strategies may be talking with friends and family, accessing support services, retaining hope and focussing on the positives. Lipinski et al. (2006) reported that parents would have liked Genetic Counsellors to have more hope and encouragement. This is not limited to hope that a diagnosis will be made, but also hope for the future, even in the absence of a diagnosis (e.g. in what support their child may obtain and hope for prognosis) (Graungaard \& Skov, 2007).

Signposting to other sources of support. Feelings of isolation and not knowing where to turn for support were often cited as reasons for seeking a diagnosis (Lewis et al., 2010; Rosenthal et al., 2001). Parents report a lack of information about what educational, social and psychological help is available (Heiman, 2002). If a Genetic Counsellor is aware of the local groups and resources available, these can be provided. Resources could be provided that contain a broad range of information, such as the roles of different healthcare providers, about educational support and benefits for children with developmental disorders. For example, the support group Unique (www.rarechromo.org) has a useful booklet called 'After diagnosis: What happens next? The early years'.

Support groups can provide peer-support for families in a similar situation. In the UK, the support group 'Syndromes Without A Name (SWAN) UK' (www.undiagnosed.org.uk) has been formed specifically for families of children without a diagnosis.

Support groups can also be a useful source of information about relevant research projects (Limb et al., 2010). Patients report that they rarely hear of research opportunities relating to their condition from clinicians (Limb et al., 2010). This is understandable to an extent as it is challenging for clinicians to stay abreast of all relevant opportunities when dealing with multiple conditions. Therefore, this should be highlighted to patients as a benefit of being part of a support group. Many families who were recruited to the DDD study first heard of it through SWAN UK (Hazelton \& Petchey, 2015).

For families affected by very rare or novel conditions, such groups may not exist and feelings of isolation can persist (Rosenthal et al., 2001). In the UK, some more general support groups exist such as Rare Disease UK (www.raredisease.org.uk), and Unique (www.rarechromo.org). Unique was originally set up for families affected by rare chromosomal abnormalities. However, they have now broadened their spectrum to include families 
affected by very rare autosomal dominant single gene disorders, where a more specific support group does not yet exist (Unique, 2018). For these families, the challenges can be very similar to those with rare chromosomal conditions and the peersupport reduces feelings of isolation, which can be immensely empowering (Limb et al., 2010).

In time it is likely that new information and/or tests will become available as research continues (Lipinski et al., 2006). It would be important to emphasize to families of the option of a review appointment in Clinical Genetics if any new symptoms or features arise; when questions arise again such as the child reaching adulthood and possibly leaving home; or when siblings reach reproductive age. This will also hopefully lessen any feelings of abandonment.

\section{Conclusion}

In the age of advanced genetic technologies, expectations have never been higher about the diagnostic potential for individuals with developmental disorders. However, a diagnosis will not necessarily provide all of the answers sought. In addition, the search for a diagnosis could be hindering a family's ability to accept their child's condition. Without appropriate support, the process of coping and adaptation could be prolonged or even unsuccessful. Genetic Counsellors have the skills to provide the support required to address the uncertainties families face, help identify areas where peer support can be found and increase perceived control, facilitating adaptation to improve individual and family functioning. This service could be provided in a specific post-test clinic to which families could be referred. Whilst Genetic Services in the UK may currently not have the resources to facilitate such an extended support service due to current demands, Genomics is an area of great development and now is the time to ensure the role of the Genetic Counsellor is optimised for these families. I believe this type of service is the very essence upon which the Genetic Counselling profession was built and it is vitally important for these families that this support is integrated into genomic testing so their psychosocial needs are not neglected in the flood of genomic information.

\section{Grant information}

The author(s) declare that no grants were involved in supporting this work.

\section{Acknowledgements}

This paper was completed as part of a portfolio for professional registration with the Genetic Counsellor Registration Board (GCRB). I would like to thank Dr Nicki Taverner for her supervision and guidance in writing this paper. I would also like to thank the GCRB and the All Wales Medical Genetics Service for their support.
Association of Genetic Nurses and Counsellors (AGNC): Train to be a Genetic Counsellor in the UK. 2018; Accessed 13th August 2018.

Reference Source

Austin J, Semaka A, Hadjipavlou G: Conceptualizing genetic counseling as psychotherapy in the era of genomic medicine. J Genet Couns. 2014; 23(6): 903-909.

PubMed Abstract | Publisher Full Text | Free Full Text

Barnett D, Clements M, Kaplan-Estrin M, et al.: Building new dreams Supporting parents' adaptation to their child with special needs. Infants Young Child. 2003; 16(3): 184-200.

Publisher Full Text

Biesecker BB: Goals of Genetic Counseling. Clin Genet. 2001; 60(5): 323-330. PubMed Abstract | Publisher Full Text

Catanzaro SJ, Mearns J: Measuring generalized expectancies for negative mood regulation: initial scale development and implications. $J$ Pers Assess. 1990; 54(3-4): 546-63.

PubMed Abstract | Publisher Full Text

Daily DK, Ardinger $\mathrm{HH}$, Holmes GE: Identification and evaluation of mental retardation. Am Fam Physician. 2000; 61(4): 1059-1067, 1070.

PubMed Abstract

Deciphering Developmental Disorders Study: Large-scale discovery of novel genetic causes of developmental disorders. Nature. 2015; 519(7542): 223-8. PubMed Abstract | Publisher Full Text | Free Full Text

Firth HV, Wright CF, DDD Study: The Deciphering Developmental Disorders (DDD) study. Dev Med Child Neurol. 2011; 53(8): 702-703.

PubMed Abstract | Publisher Full Text

Genomics England: The 100,000 Genomes Project. 2018; Accessed 20th November 2018.

Reference Source

Graungaard AH, Skov L: Why do we need a diagnosis? A qualitative study of parents' experiences, coping and needs, when the newborn child is severely disabled. Child Care Health Dev. 2007; 33(3): 296-307.

PubMed Abstract | Publisher Full Text

Hazelton A, Petchey L: Genome Sequencing: What do patients think? Patient

Charter. Genetic Alliance UK. 2015.

Reference Source
Heiman T: Parents of children with disabilities: Resilience, Coping and Future Expectations. J Dev Phys Disabil. 2002; 14(2): 159-171.

Publisher Full Text

Kandel I, Merrick J: The child with a disability: parental acceptance, management and coping. ScientificWorldJournal. 2007; 7: 1799-1809. PubMed Abstract | Publisher Full Text | Free Full Text

Kearney PM, Griffin T: Between joy and sorrow: being a parent of a child with developmental disability. J Adv Nurs. 2001; 34(5): 582-592.

PubMed Abstract | Publisher Full Text

Kessler S: Psychological Aspects of Genetic Counseling. IX. Teaching and

Counseling. J Genet Couns. 1997; 6(3): 287-295.

PubMed Abstract | Publisher Full Text

Lee H, Deignan JL, Dorrani N, et al.: Clinical exome sequencing for genetic identification of rare Mendelian disorders. JAMA. 2014; 312(18): 1880-1887. PubMed Abstract | Publisher Full Text | Free Full Text

Lerner B, Roberts JS, Shwartz M, et al.: Distinct communication patterns during genetic counseling for late-onset Alzheimer's risk assessment. Patient Educ Couns. 2014; 94(2): 170-179.

PubMed Abstract | Publisher Full Text | Free Full Text

Lewis C, Skirton H, Jones R: Living without a diagnosis: The parental experience. Genet Test Mol Biomarkers. 2010; 14(6): 807-815.

PubMed Abstract | Publisher Full Text

Limb L, Nutt S, Sen A: Experience of rare diseases: An insight from patients and families. Rare Disease UK. 2010.

Reference Source

Lipinski SE, Lipinski MJ, Beisecker LG, et al: Uncertainty and perceived personal control among parents of children with rare chromosome conditions: the role of genetic counseling. Am J Med Genet C Semin Med Genet. 2006; 142C(4): 232-240.

PubMed Abstract | Publisher Full Text

Madeo AC, O'Brien KE, Bernhardt BA, et al: Factors associated with perceived uncertainty among parents of children with undiagnosed medical conditions. Am J Med Genet A. 2012; 158A(8): 1877-1884.

PubMed Abstract | Publisher Full Text | Free Full Text

Makela NL, Birch PH, Friedman JM, et al.: Parental perceived value of a diagnosis for intellectual disability (ID): a qualitative comparison of families 
with and without a diagnosis for their child's ID. Am J Med Genet A. 2009; 149A(11): 2393-402.

PubMed Abstract | Publisher Full Text

Meiser B, Irle J, Lobb E, et al:: Assessment of the content and process of genetic counseling: a critical review of empirical studies. J Genet Couns. 2008 17(5): 434-451.

PubMed Abstract | Publisher Full Text

Middleton A, Hall G, Patch C: Genetic Counselors and Genomic Counseling in the United Kingdom. Mol Genet Genomic Med. 2015; 3(2): 79-83.

PubMed Abstract | Publisher Full Text | Free Full Text

Middleton A, Marks $\mathrm{P}$, Bruce $\mathrm{A}$, et al:: The role of genetic counsellors in genomic healthcare in the United Kingdom: a statement by the Association of Genetic Nurses and Counsellors. Eur J Hum Genet. 2017; 25(6): 659-661.

PubMed Abstract | Publisher Full Text | Free Full Text

Miller DT, Adam MP, Aradhya S, et al.: Consensus statement: chromosomal

microarray is a first-tier clinical diagnostic test for individuals with

developmental disabilities or congenital anomalies. Am J Hum Genet. 2010; 86(5): 749-764.

PubMed Abstract | Publisher Full Text | Free Full Text

Rauch A, Hoyer J, Guth S, et al:: Diagnostic yield of various genetic approaches in patients with unexplained developmental delay or mental retardation. $\mathrm{Am} \mathrm{J}$ Med Genet A. 2006; 140(19): 2063-2074.

PubMed Abstract | Publisher Full Text

Rosenthal ET, Biesecker LG, Biesecker BB: Parental attitudes toward a diagnosis in children with unidentified multiple congenital anomaly syndromes. $A m J$
Med Genet. 2001; 103(2): 106-114

PubMed Abstract | Publisher Full Tex

Roter D, Ellington L, Erby LH, et al: The Genetic Counseling Video Project (GCVP): Models of Practice. Am J Med Genet C Semin Med Genet. 2006; 142C(4): 209-220

PubMed Abstract | Publisher Full Text | Free Full Text

Shavell M, Ashwal S, Donley D, et al:: Practice parameter: evaluation of the child with global developmental delay: report of the Quality Standards

Subcommittee of the American Academy of Neurology and The Practice Committee of the Child Neurology Society. Neurology. 2003; 60(3): 367-380. PubMed Abstract | Publisher Full Text

Unique: Welcome to Unique. 2018; Accessed 20th November 2018

Reference Source

Walser SA, Werner-Lin A, Mueller R, et al:: How do providers discuss the results of pediatric exome sequencing with families? Per Med. 2017; 14(5): 409-422.

PubMed Abstract | Publisher Full Text | Free Full Text

Wang Z, Liu X, Yang BZ, et al.: The role and challenges of exome sequencing in studies of human diseases. Front Genet. 2013; 4: 160

PubMed Abstract | Publisher Full Text | Free Full Text

Welsh Government: Genomics for Precision Medicine Strategy. 2017; Accessed 29th October 2018.

Reference Source

Wynn J: Genomic Testing: a Genetic Counselor's Personal Reflection on Three Years of Consenting and Testing. J Genet Couns. 2016; 4: 691-697.

PubMed Abstract | Publisher Full Text | Free Full Text 


\section{Open Peer Review}

\section{Current Peer Review Status:}

\section{Version 2}

Reviewer Report 17 January 2019

https://doi.org/10.5256/f1000research.18833.r42020

(C) 2019 Ingvoldstad Malmgren C. This is an open access peer review report distributed under the terms of the Creative Commons Attribution License, which permits unrestricted use, distribution, and reproduction in any medium, provided the original work is properly cited.

\section{Charlotta Ingvoldstad Malmgren}

${ }^{1}$ Department of Public Health and Caring Sciences, Uppsala University, Uppsala, Sweden

2 Clintec, Karolinska University Hospital, Stockholm, Sweden

I think it is much better structured, and easily read now. I also think it is good that the manuscript now focuses more on the post-test counselling and I really see the value of genetic counsellors in this process.

I think this aspect of counselling is very important and I am happy that the author highlights this area of work setting for genetic counsellors and hope that clinical genetic clinics can benefit from this article in building their organisations.

After the revisions made I now approve the manuscript for indexing in F1000.

Is the topic of the opinion article discussed accurately in the context of the current literature?

Partly

Are all factual statements correct and adequately supported by citations? Yes

Are arguments sufficiently supported by evidence from the published literature? Partly

Are the conclusions drawn balanced and justified on the basis of the presented arguments? No

Competing Interests: No competing interests were disclosed.

I confirm that I have read this submission and believe that I have an appropriate level of 
expertise to confirm that it is of an acceptable scientific standard.

Reviewer Report 11 January 2019

https://doi.org/10.5256/f1000research.18833.r42021

(C) 2019 Cuthbert . This is an open access peer review report distributed under the terms of the Creative Commons Attribution License, which permits unrestricted use, distribution, and reproduction in any medium, provided the original work is properly cited.

\section{Andrew Cuthbert}

Cardiff University, Cardiff, UK

Very much improved, thank you!

Although not relevant to reviewing this manuscript, I feel there is a debate to be had about the relative merits of genetic counsellors as opposed to other disability oriented health professionals (who see many more disabled children and their families with both acquired and genetically driven disabilities), third sector support groups, virtual/online/interactive resources, others, to best support families who are considered to be in need. A strong focus on health and social outcomes would have a priority. Perhaps, something a well designed research study could investigate? It would also be helpful to understand what hard-pressed parents (the ones who rarely engage in research!) actually want, what are their priorities. Addressing their social circumstances by other means, through education (a generational issue) and social care (more immediate) might improve their self-perception and sense of control over these difficult matters, and, vitally, their children's developmental outcomes.

A few minor comments:

1. A formal definition of ID in the intro (alongside the given definition of DD) would be valuable.

2. Diagnostic yields achieved 50-70\% WITH (not UNTIL) the advent of arrays and sequencing.

3. "...often results in an extended period of coping and adaptation...", but surely the coping is life long? Suggest say "protracted period for acceptance and adaptation".

'Referral criteria':

The family have lower levels of perceived control/increased levels of uncertainty - How would this be formally and equitably assessed? Is the LOT-R validated for perceived control? It was designed more to assess optimism vs pessimism, is this a valid surrogate of personal control?

The family have a lack of social support - Designing a fair and equitable disability oriented social deprivation risk assessment tool would be enormously challenging, history shows.

The affected person has a novel or very rare diagnosis about which little information is known - very difficult to equitably delineate this. Rare does not equate with complexity of care, extent of disability, impact on family. Consider the huge variation in 
presentation children diagnosed with the same CNV syndrome.

The affected person remains undiagnosed. - Should always be in follow-up and/or a research study.

4. Generally, try not to cite the same reference multiple times, ie Lipinski 2006, Madeo 2012, Middleton 2015. Use other sources.

Is the topic of the opinion article discussed accurately in the context of the current literature?

No

Are all factual statements correct and adequately supported by citations? No

Are arguments sufficiently supported by evidence from the published literature? No

Are the conclusions drawn balanced and justified on the basis of the presented arguments? No

Competing Interests: No competing interests were disclosed.

Reviewer Expertise: genetic counselling, psychiatry

I confirm that I have read this submission and believe that I have an appropriate level of expertise to confirm that it is of an acceptable scientific standard.

\section{Version 1}

Reviewer Report 09 July 2018

https://doi.org/10.5256/f1000research.15473.r34842

(c) 2018 Cuthbert . This is an open access peer review report distributed under the terms of the Creative Commons Attribution License, which permits unrestricted use, distribution, and reproduction in any medium, provided the original work is properly cited.

\section{Andrew Cuthbert}

Cardiff University, Cardiff, UK

Title

Too long and tentative, be succinct and give a definite message to attract the reader.

Aim

Needs a clearer definition of the aims. Is it to define the challenges faced by parents of children with DDs, diagnosed or otherwise, as well as the how well genetic counsellors address these 
issues? Key aim is a justification for extending genetic counsellor's role in the post genomic diagnosis period, make this very clear early on. Needs to consider and compere alternative models of family support.

\section{Structure}

Somewhat confused, needs clearly define and describe each topic and refrain from commentary therein, rather to have clearly subtitled commentary paragraphs where appropriate, either as a standalone section or at the end of each topic, and be consistent.

\section{Introduction}

Unnecessary detail on definitions of DD and ID, some of which is inaccurate. Should think about the audience who may not be familiar with jargon such as exome sequencing. It would help to describe typical referral pathways to clinical genetics, most referral for DD/ID are from paediatric neurology services who frequently request array tests and return results prior to visiting genetics. How will this change, if at all, as genome sequencing is commissioned into the NHS. IS there a different perspective in the US, Europe, elsewhere?

The description of diagnostic measures and yields is misleading. The focus ought, to be, briefly, on the yield (actually 15-23\%) of current methods in use in UK services (or wherever the author feels this is relevant). Clinical microarray was originally commissioned in around 2007 (NHS England), ie it's not so modern. Then should describe potential impacts of integrating exome/genome sequencing with increased genomic diagnoses (around 70\%) and how this will impact current GC practice.

Needs a paragraph on the psychosocial imperatives of a genetic diagnosis/non-diagnosis and the role of GCs (or others) in counselling for this. Following this present a concluding paragraph outlining the commentary's aims and objectives - and why there is, arguably, any need to change current practice.

\section{Genetic Counsellors and Genetic Counselling}

Genetic counsellors are not the sole providers of genetic counselling (needs also to acknowledge clinical geneticists have been counselling families for as long as GCs). The commentary should be cognisant of the role of nurse specialists who provide counselling, ie that genetic counselling is not the exclusive the domain of trained GCs.

Since developments in genome technology are inevitably influencing developments in service design and delivery, in the UK and other countries, the author should consider their impact on GC roles in supporting families post-diagnosis - as pre-test counselling becomes increasingly obsolete as has been happening for several years due primarily to technological developments and their superior diagnostic accuracy. Argue whether any change in service delivery might be justifiable.

\section{Support}

The author should recognise and comment that a majority, probably vast majority, of families engage support from places other than clinical genetics, especially over the medium-long term. Genetics services role in supporting families is circumscribed and predominantly short-term.

The nature of support is vaguely described, what exactly is the support given in a genetic 
counselling encounter (by a genetic counsellor or other practitioner) which would facilitate improved adjustment and where is the justification to develop a specialist post-test/post-genomic diagnosis support service as distinct from routine follow-up. A significant Would this be a genetic counsellor led service? How would this differ from current open-door policy where parents are able to access follow-up contact with the clinician/practitioner. The author could consider how signposting and information content and provision could be improved, particularly how to ensure support group contact is increased, training for rare disease support groups to tackle complexities associated with single gene diagnoses for DD/ID after exome/genome sequencing, as with 100k genomes. Arguably, well informed peer/third sector support is more accessible, immediate and broader in relevance than highly specialised genetic counsellors/clinical specialists and perhaps better placed to facilitate longer term 'community' support, family acceptance and adjustment.

Psychological support for families with children with severe/life limiting illness, more generally, isn't dependent on the disease specialist being trained to provide such additional 'support/care'. Arguably this applies to aspects of rare disorders care ad management. Moreover, given the extent and complexity of mental health risks, impacts and needs of children with DD/ID, combined with the psychological and social struggles of their parents/carers, who experience high levels of anxiety, depression and trauma (as the author acknowledges), are there alternative models of 'support' which are more rigorous and wide-ranging than conventional genetics follow-up, for which mental health and voluntary sector providers would be better placed to provide? A clear definition of the purpose, content and contextual relevance of 'support' needs to be given, as forms the basis of the authors justification for a significant change in service.

\section{Conclusion}

This is a thought provoking commentary on a subject of increasing importance and at a time when genomic medicine's relevance and promise to improve lives is subject to intense scrutiny, presented at a time when certain aspects clinical genetics services are experiencing perceived existential threats. Despite its shortcomings, need for structural correction and lack of coherent justification for what would be a significant change to current service provision which is counter to the evolving emphasis of genetic counselling training programmes, this kind of commentary is welcome and strongly supported. A revised version would be very welcome.

\section{Is the topic of the opinion article discussed accurately in the context of the current literature?}

Partly

\section{Are all factual statements correct and adequately supported by citations?}

Yes

Are arguments sufficiently supported by evidence from the published literature? Partly

Are the conclusions drawn balanced and justified on the basis of the presented arguments? Partly

Competing Interests: No competing interests were disclosed. 
Reviewer Expertise: genetic counselling, psychiatry

\section{I confirm that I have read this submission and believe that I have an appropriate level of expertise to confirm that it is of an acceptable scientific standard, however I have significant reservations, as outlined above.}

Reviewer Report 28 June 2018

https://doi.org/10.5256/f1000research.15473.r34843

(C) 2018 Kenwrick S et al. This is an open access peer review report distributed under the terms of the Creative Commons Attribution License, which permits unrestricted use, distribution, and reproduction in any medium, provided the original work is properly cited.

\section{Vicki Wiles}

Addenbrookes Hospital, Cambridge, UK

Sue Kenwrick

Addenbrookes Hospital, Cambridge, UK

\section{Comments by Sue Kenwrick, Principal Genetic Counsellor}

The author sets out some of the potential implications for families with a child affected by a developmental disorder who are undergoing broad genetic testing such as array CGH or exome analysis. She proposes an increased role for genetic counsellors (GCs) in helping families adapt to genetic test results and proposes a model where GCs hold clinics prior to genetic testing to help manage patient expectations and to identify individual family needs.

The background overview of the impact of having a child with a developmental disorder, the search for a diagnosis and research into factors that help or hinder adjustment is thought provoking and well structured. The author should also mention large projects doing whole genome as well as exome analysis for completion (such as 100,000 genome project).

She sets out well the complex needs of families in these situations and the need to pay attention to emotional needs (counselling) as well as educational needs (teaching) of parents going through testing. In particular, she highlights the need for management of expectations surrounding a test and a need to signpost/refer parents to additional resources/support groups that may further facilitate adjustment and coping. Clearly, these families would benefit from incorporation of more of the 'counselling' aspect of their consultations in order to optimise their adjustment. However, there is more than one way this could be achieved. Personally I think the idea of introducing a 'preconsultation' with a GC prior to broad genetic testing by another clinician (as suggested in the authors model) is a retrograde step for the profession. I think this would be a great strain on limited GC availability at a time when we are taking steps to deal with increase in referrals by doing more genetic counselling by telephone. For many genetic services models already exist for pregathering of information by family history questionnaire for certain conditions and some of this is done by coordinators that are not trained in genetic counselling. This non-GC workforce would not be equipped to ask about family coping strategies or perceived control as seems to be implied in the authors model (under initial contact).

While it is valid and laudable to highlight GC input and support for families with a new diagnosis or uncertain result, I don't think this shift in service provision provides the answer. Rather, any 
provider (whether Clinical Geneticist or GC) offering a genetic investigation should be equipped to discuss managing expectations and support the family by signposting to resources or offering additional consultations, or referrals as required. Depending on the centre, It is already common for GCs to see families after a 'genomic' result to facilitate understanding and assess the families further needs and this could be an open offer or case by case. Additional training is something that might be required for some providers. Another part of the solution could be multimedia resources that facilitate the process of testing and follow-up (e.g. online videos about having a genetic test and how it doesn't always give a clear answer or improved follow-up literature for families). There is no doubt, however, that, as the author points out, GCs are skilled at managing the psychosocial aspects of genetic counselling and there will be a need to increase the workforce as more complex genetic investigations and results are provided.

For readers outside clinical genetics services, I think the author should distinguish between the terms genetic counselling and genetic counsellor, as this can be confusing for those in other specialties. Genetic counselling is done by different types of provider (Clinical Geneticists, GCs and, in some specialties, by specialist nurses who have had genetics training). Genetic counsellors, however, are a body of allied health professionals from science or nursing background, 'usually' not MDs, who are trained in genetic counselling.

Overall, as this is an opinion piece and raises interesting issues surrounding broad genetic testing. I approve publication with reservation based on a limited exploration or potential solutions and significant reservation about the model proposed.

\section{Comments by Vicki Wiles, Consultant Genetic Counsellor}

This review and opinion piece by a Genetic Counsellor from the Wales Genetic Counselling service raises interesting questions about the use of Genetic Counselling resources. The support and counselling issues for families with children with disorders of developmental are well described and the summary of research papers supports the argument that Genetic Counsellors are well trained in counselling skills, with an understanding of genetic concepts and testing and are therefore equipped to help families with children with undiagnosed disorders. I would agree that there is often a need for support that a GC can provide but this support might also be provided by the family Health Visitor, a paediatric Clinical Nurse Specialist or the Consultant Geneticist working with the family.

I would have liked to see more discussion on how genetic counselling varies across England and the devolved Countries, with an acknowledgement that some services have continued to do preclinic work sometimes including home visits, with longer term involvement, while other services have moved to more autonomous working for Genetic Counsellors focussing more on genetic testing where there is known diagnosis in the family. Funding and workforce differences in England have influenced the type of work that genetic counsellor's focus on and I would have welcomed reference to this. The article would benefit from a broader health resources overview to set the author's views in context including the financial side to her argument, which might well underpin her views. As genomics moves more into mainstream medicine there will be many, possibly conflicting, demands on genetic counsellor's time with patients and so this article is timely and merits publication to stimulate debate.

\section{Is the topic of the opinion article discussed accurately in the context of the current literature? \\ Yes}

Are all factual statements correct and adequately supported by citations? 
Yes

Are arguments sufficiently supported by evidence from the published literature? Partly

Are the conclusions drawn balanced and justified on the basis of the presented arguments? Partly

Competing Interests: No competing interests were disclosed.

We confirm that we have read this submission and believe that we have an appropriate level of expertise to confirm that it is of an acceptable scientific standard, however we have significant reservations, as outlined above.

Reviewer Report 22 May 2018

https://doi.org/10.5256/f1000research.15473.r32695

(c) 2018 Ingvoldstad Malmgren C et al. This is an open access peer review report distributed under the terms of the Creative Commons Attribution License, which permits unrestricted use, distribution, and reproduction in any medium, provided the original work is properly cited.

\section{Maria Soller}

Clinical genetics, Karolinska University Hospital, Stockholm, Sweden

Charlotta Ingvoldstad Malmgren

1 Department of Public Health and Caring Sciences, Uppsala University, Uppsala, Sweden

2 Clintec, Karolinska University Hospital, Stockholm, Sweden

Thank you for giving me the opportunity to review this manuscript.

I think that this article highlights several important aspects. New genomic technologies will add to the complexity of genetic disorders. Both pre-test and post-test counselling are of great importance to understand what information the new technologies can bring as well of course the limitations of the tests and results.

I do also think as the writer states that patients as well as relatives might need even more support related to the results (both when no diagnosis is set or when a very rare diagnosis is found, there is limited knowledge is present).

It is thus important to be able to help and support the patients in that situation and as the author states in a citation; receiving the result can be not the end but the start of the journey. Genetic counsellors' roles might also change and develop in this genomic area.

So as a subject I think this is an important paper. However, I have some major issues regarding this paper, which need major revisions prior to possible indexing: 
$\underline{\text { Title }}$

I think the title is long and not very clear. I think it needs to be shortened, given a more focused topic.

$\underline{\text { Aim }}$

For me the aim (focus) of the manuscript is not completely clear. What I can see there are two different focuses:

1) What support do these parents need regarding acceptance and coping

2) How can genetic counsellors take part in this area

I think the manuscript should benefit from either focus on one of those aims OR to clarify that there are 2 aims/focuses.

\section{Structure}

The manuscript should benefit from changing the structure of the text. I think it is a little unstructured moving back and forward between things.

\section{Introduction}

I think the introduction is too long and to detailed on the different definitions on ID. It is not necessary for the aims of the manuscript.

I would also change the order of the subtitles of the introduction. After the first part on the definition and prevalence I think it would be more relevant of having the section on "Diagnostic Tools". I think that this part also can be shortened.

Then I think that the section on parental responses and support needs to be put together as one section. There is a bit of overlap between them. Check for overlaps. I do think the section on the different coping issues is very good and relevant.

At the end of the left column page 3 I would change the focus from "how it will affect the role of genetic counsellors....." to how it would affect the need for support and genetic counselling and if so, how genetic counsellors can participate in this area of support.

\section{Role of genetic counsellors}

I think it is a very interesting approach that GCs can play a role here. However it lacks discussions on what unique skills GCs have to take this role. What is included in GC education? The author talks in a sentence about that GCs need to be more prepared to do this and that the current knowledge is not sufficient and that further education might be needed. I would like to see a development of the discussion on this and references to studies on the education and role of genetic counsellors.

\section{Example}

I do believe that it is good to show things by examples and I think the citations from parents is a good ways of showing parents thoughts and experiences. However, for me the example of childhood overgrowth stands a little on it is own and does not add very much here. I recommend to take that out.

\section{Conclusion}


I think the conclusion could be clearer and should benefit from clarifying the aim/aims of the study.

In summary, I think it is an interesting paper within an interesting area, but which needs major revision to be indexed.

Is the topic of the opinion article discussed accurately in the context of the current literature?

Partly

Are all factual statements correct and adequately supported by citations? Yes

Are arguments sufficiently supported by evidence from the published literature? Partly

Are the conclusions drawn balanced and justified on the basis of the presented arguments? No

Competing Interests: No competing interests were disclosed.

We confirm that we have read this submission and believe that we have an appropriate level of expertise to confirm that it is of an acceptable scientific standard, however we have significant reservations, as outlined above.

Author Response 25 May 2018

Flora Joseph, All Wales Medical Genetics Service, UK

Thank you very much for reviewing my article. You make some valuable points and I will look to revise the article and incorporate them.

Competing Interests: None 
The benefits of publishing with F1000Research:

- Your article is published within days, with no editorial bias

- You can publish traditional articles, null/negative results, case reports, data notes and more

- The peer review process is transparent and collaborative

- Your article is indexed in PubMed after passing peer review

- Dedicated customer support at every stage

For pre-submission enquiries, contact research@f1000.com 